\title{
Autochthonous dengue outbreak in Nîmes, South of France, July to September 2015
}

T Succo $^{1}$, I Leparc-Goffart ${ }^{2}$, J Ferré ${ }^{3}$, D Roiz ${ }^{4}$, B Broche ${ }^{5}$, M Maquart $^{2}$, H Noel ${ }^{6}, 0$ Catelinois ${ }^{1}$, F Entezam ${ }^{5}$, D Caire ${ }^{3}$, F Jourdain ${ }^{7}$, I Esteve-Moussion ${ }^{5}$, A Cochet ${ }^{1}$, C Paupy ${ }^{4}$, C Rousseau ${ }^{1}$, M Paty $^{6}$, F Golliot $^{1}$

1. Regional office of the French Public Health Agency (Cire Languedoc-Roussillon Midi-Pyrénées), Montpellier, France

2. Institut de Recherche Biomédicale des Armées, National Reference Laboratory for arboviruses, Marseille, France

3. Entente Interdépartementale pour la Démoustication du littoral Méditerranéen (EID Méditerranée), Public mosquito control operator, Montpellier, France

4. Laboratory MIVEGEC (UMR 224-5290 CNRS-IRD-UM), Montpellier, France

5. Regional Health Agency of Languedoc-Roussillon Midi-Pyrénées, Montpellier, France

6. The French Public Health Agency (Santé publique France), Saint-Maurice, France

7. French National Centre of Expertise on Vectors, Montpellier, France

Correspondence: Tiphanie Succo (tiphanie.succo@ars.sante.fr)

Citation style for this article:

Succo T, Leparc-Goffart I, Ferré J, Roiz D, Broche B, Maquart M, Noel H, Catelinois O, Entezam F, Caire D, Jourdain F, Esteve-Moussion I, Cochet A, Paupy C, Rousseau C, Paty M, Golliot F. Autochthonous dengue outbreak in Nîmes, South of France, July to September 2015. Euro Surveill. 2016;21(21):pii=30240. DOI: http://dx.doi. org/10.2807/1560-7917.ES.2016.21.21.30240

Article submitted on 22 December 2015 / accepted on 10 May 2016 / published on 26 May 2016

In August and September 2015, seven locally acquired cases of dengue virus type 1 (DENV-1) were detected in Nîmes, south of France, where Aedes albopictus has been established since 2011. Epidemiological and entomological investigations allowed to steer vector control measures to contain transmission. An imported case from French Polynesia with onset fever on 4 July was identified as primary case. This outbreak occurred from 8 August to 11 September in a $300 \mathrm{~m}$ radius area. Six sprayings to control mosquitos were performed in the affected area. We describe the first considerable dengue outbreak in mainland France where only sporadic cases of autochthonous dengue were recorded previously (2010, 2013 and 2014). The 69 day-period between the primary case and the last autochthonous case suggests multiple episodes of mosquito infections. The absence of notification of autochthonous cases during the month following the primary case's symptoms onset could be explained by the occurrence of inapparent illness. Recurrence of cases every year since 2013, the size of the 2015 outbreak and continuing expansion of areas with presence of Ae. albopictus highlight the threat of arboviral diseases in parts of Europe. Thus, European guidelines should be assessed and adjusted to the current context.

\section{Background}

Dengue viruses are usually transmitted in tropical areas by Aedes mosquitoes, primarily by Aedes aegypti and secondarily by Ae. albopictus [1]. In the European Basin, autochthonous transmission of dengue was not recorded from 1945 to 2010 mainly due to the disappearance of Ae. aegypti after the 1950s. The introduction of Ae. aegypti in 2005 in Madeira facilitated the occurrence of a large outbreak with more than 2,000 cases on the island in the Atlantic Ocean, in $2012[2,3]$. During the last four decades, Ae. albopictus has been reported in 20 European countries, mainly located in the Mediterranean basin [4]. Sporadic cases and pairs of cases of local dengue transmission have been reported in France in 2010, 2013 and 2014 [5-7]. In Croatia, an outbreak of dengue occurred in 2010 with laboratory evidence of recent infection in 17 people [8].

Following the establishment of Ae. albopictus in France in 2004, and given its potential as a vector of the dengue (DENV) and chikungunya (CHIKV) viruses, a national preparedness and response plan to prevent and control local transmission of chikungunya and dengue in mainland France was put in place in 2006 and has been updated every year since then [9]. It includes monitoring the geographical distribution of Ae. albopictus during the period of vector activity from May to November, and enhancing human surveillance - based on notification of suspected imported cases of dengue and/or chikungunya, and of confirmed autochthonous cases - in the districts where the vector is established.

\section{The alert}

On the 14 August 2015, two autochthonous cases of dengue were notified by the laboratory of virology of Nîmes University Hospital to the regional health authorities of Languedoc-Roussillon, an administrative region in the south of France. Real-time reverse transcriptase polymerisation chain reaction (RT-PCR) performed on samples taken 6 days after the onset of symptoms showed that both cases were positive for DENV. The two patients were around 20 years old and lived in the same house on the outskirts of Nîmes, in 
the Gard administrative district (a subdivision of the administrative region of Languedoc-Roussillon). On 8 August 2015, they both developed a sudden high-grade fever $\left(>38.5^{\circ} \mathrm{C}\right)$ with headache, retro-orbital pain, myalgia, rash and asthenia. They had no travel history to dengue endemic or epidemic areas. Both were hospitalised from 13 to 17 August 2015. The French National Reference Centre (NRC) for arboviruses in Marseille, confirmed the diagnosis of dengue on 19 August by real-time RT-PCR, and characterised the virus serotype as DENV-1.

In line with the guidelines set down in the national preparedness and response plan, immediate epidemiological and entomological investigations were performed in order to contain transmission.

\section{Methods}

\section{Epidemiological investigations}

Imported dengue cases previously recorded in the surveillance database were retrospectively analysed to identify a potential primary case. All imported dengue cases identified during the 2015 season in LanguedocRoussillon living near or visiting the same places where the two autochthonous cases lived, were listed.

For the investigation, the following case definitions of autochthonous dengue were applied. In the Gard administrative district as of 1 July 2015:

- A suspected case was defined by a sudden highgrade fever $\left(>38.5^{\circ} \mathrm{C}\right)$ associated with one of the following clinical signs (headache, myalgia, arthralgia, lower back pain, retro-orbital pain) which could not be explained by another medical condition, in a person with no history of travel to dengue endemic or epidemic areas in the 15 days before the onset of symptoms.

- A probable case was defined as a suspected case with an epidemiological link to a confirmed case (i.e. living in the same household as a confirmed imported or autochthonous case).

- A confirmed case was defined as a suspected case with positive laboratory tests (real-time RT-PCR or positive serology for IgM and IgG antibodies to DENV) performed by the NRC.

Active case finding was implemented on 20 August 2015 and included (i) door-to-door surveys in a $200 \mathrm{~m}$ radius around the index cases' residence, with neighbours being interviewed about any episodes of high temperature they may have had since 1 July, (ii) providing information and instruction to physicians and laboratories so that they could notify all suspected cases of dengue (imported and autochthonous) and (iii) phone calls to the 22 general practitioners working in a $1.5 \mathrm{~km}$ radius around the index cases' residence.
Health authorities and epidemiologists interviewed all suspected, probable and confirmed dengue cases.

For each new suspected case identified, blood samples were collected for analysis by the NRC. Real-time RT-PCR was performed on samples collected within 7 days after symptoms onset. Serology was performed when samples were collected more than 5 days after the onset of symptoms.

\section{Entomological investigation and vector control measures}

Entomological investigations were performed to guide vector control measures. Interviews focused on cases' (probable and confirmed) movements during their viraemic period ( 1 day before and 7 days after symptoms onset), including home, workplace, work-related travel, visits to friends and family and medical consultations. Control measures included the search for and elimination of possible larval breeding sites (by emptying water from containers or by using Bti), and ultra-low-volume spraying of deltamethrin (Cerathrine and Aqua K-Othrine 2 and $1 \mathrm{~g}$ of active substance ha-1, respectively) in locations frequented by the cases during their viraemia when Ae. albopictus was found.

During the door-to-door survey, entomological data were also collected to estimate the number of possible breeding sites, larvae and imagos of Ae. albopictus. The house index, usually used to describe Stegomyia mosquito infestation of a city or district, was calculated. This index is the percentage of visited houses with at least one breeding site with larvae [10]. Due to lack of time, we did not calculate other indices, for example the Breteau index (the number of larvaepositive containers per 100 houses) or the container index (percentage of larvae-positive containers per 100 water-holding containers).

To assess DENV prevalence in the mosquito population in the area of autochthonous cases, a field survey with BG-Sentinel traps (with and without dry ice) was carried out twice. The first survey consisted of six traps positioned in the neighbourhood of autochthonous cases. The second survey covered a wider area (56.8 ha) and had 20 traps placed along the borders of the outbreak area. BG-traps were examined daily before and after deltamethrin treatment. Mosquito samples were transported in dry ice to the Maladies infectieuses et vecteurs: ecologie, génétique, evolution et contrôle (MIVEGEC) laboratory in Montpellier to be identified on a chill table and were stored at $-80^{\circ} \mathrm{C}$ to optimise the detection of RNA viruses. Ae. albopictus females were pooled in same day/location samples. Samples were then sent to the NRC to proceed with RNA extraction and $q R T-P C R$ to detect possible DENV. 


\section{FIGURE 1}

Timeline of symptoms onset for imported and autochthonous cases of dengue and epidemiological features, Nîmes, France, July-September $2015(\mathrm{n}=8)$

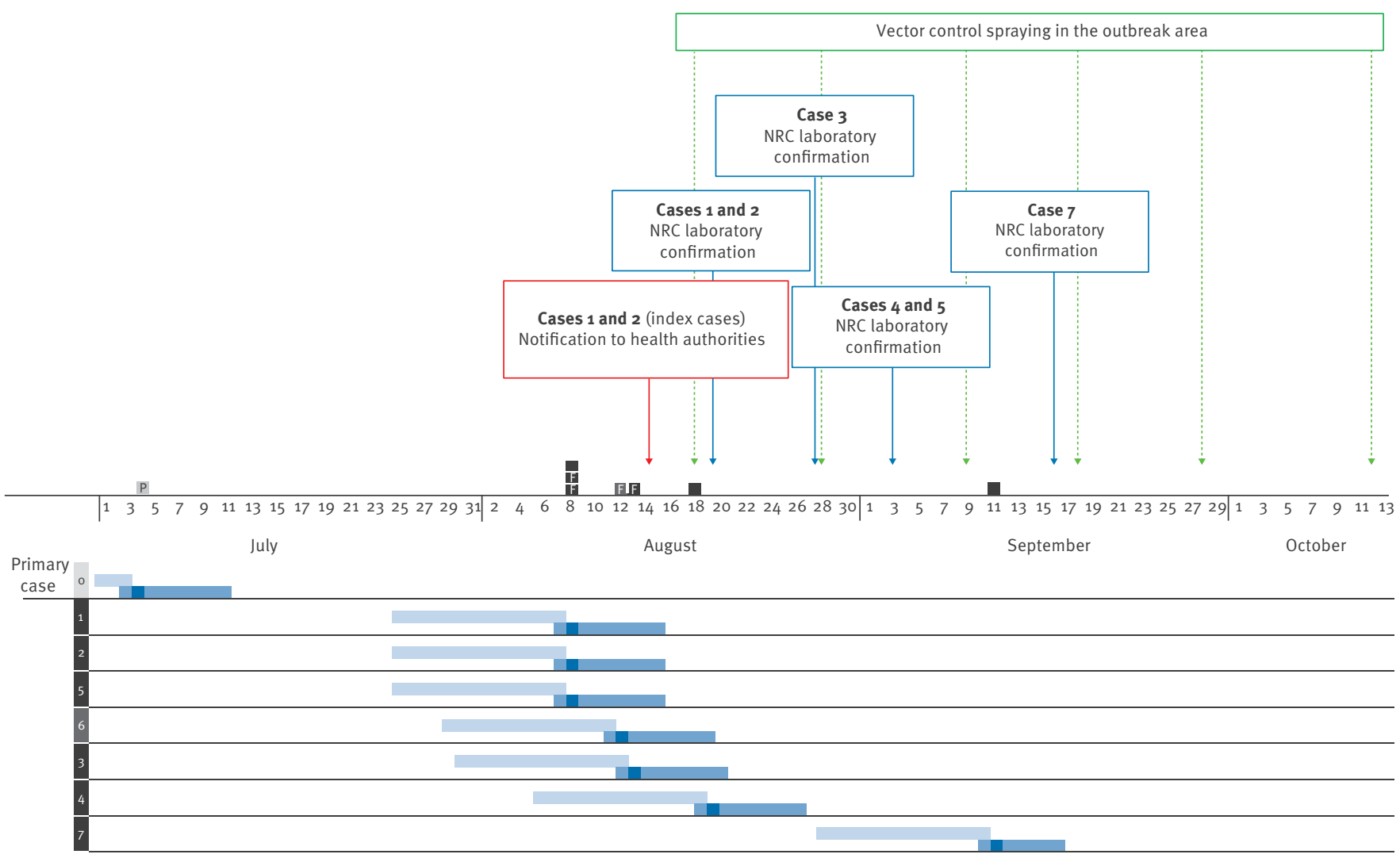

P Primary case

Autochthonous laboratory-confirmed case

Autochthonous probable case

F Family case

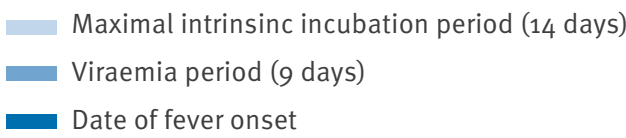

NRC: French National Reference Centre for arboviruses

\section{Results}

\section{Epidemiological investigations}

Primary case

A dengue case imported from French Polynesia was identified in the surveillance database. The patient had developed sudden high fever with a headache, asthenia and diarrhoea on 4 July 2015, 5 days after returning from French Polynesia. The diagnosis was confirmed by real-time RT-PCR by the NRC and DENV-1 was identified. The case was notified to authorities on 14 July. Entomological investigations were performed and vector control measures subsequently implemented in the areas where the patient declared he had stayed during the viraemic phase from 3 to 11 July. The patient was interviewed once again in August after the identification of the two autochthonous cases. In this interview he also recalled that he had visited friends living in the outbreak neighbourhood during the viraemic phase. As he had not mentioned this location in his first interview, no vector control measures had been implemented in this neighbourhood in July.

Active case finding

Six suspected cases were identified through door-todoor surveys on 20 August. Of these, two agreed to provide a blood sample for virological investigations: one was positive following real-time RT-PCR, the other was negative. Among the four people who did not agree to provide a blood sample - for time and/or for personal reasons - one was classified as a probable case as he resided in the same household as a confirmed case (Table 1). After door-to-door surveys, three additional cases were confirmed by the NRC among suspected autochthonous cases notified by health professionals. 


\section{FIGURE 2}

Spatial distribution of imported and autochthonous cases of dengue and vector control measures implemented, Nîmes, France, July-September $(\mathrm{n}=8)$

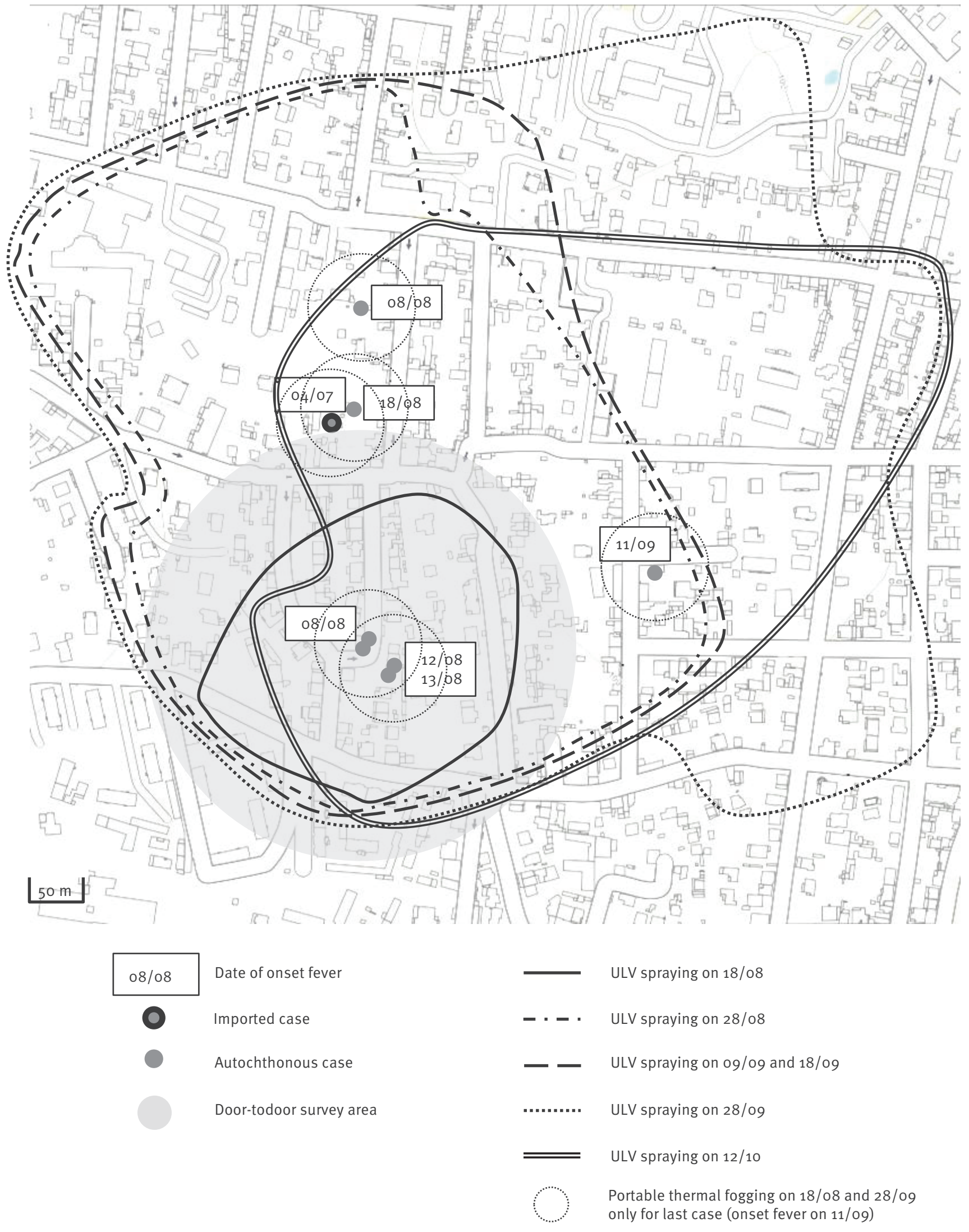

ULV: ultra-low-volume.

Note: false-base map for privacy reasons. 
Final classification and laboratory results of dengue cases, Nîmes, France, July-September 2015 (n=8)

\begin{tabular}{|c|c|c|c|c|c|c|c|c|}
\hline \multirow[t]{2}{*}{ Case number } & \multirow[t]{2}{*}{ Classification } & \multirow[t]{2}{*}{$\begin{array}{c}\text { Date of } \\
\text { symptoms onset }\end{array}$} & \multirow[t]{2}{*}{$\begin{array}{l}\text { Sampling time } \\
\text { after onset } \\
\text { (days) }\end{array}$} & \multicolumn{2}{|c|}{$\begin{array}{l}\text { Serological tests for } \\
\text { dengue }\end{array}$} & \multirow[t]{2}{*}{$\begin{array}{l}\text { Real-time } \\
\text { RT-PCR }\end{array}$} & \multirow[t]{2}{*}{ Serotype } & \multirow[t]{2}{*}{ Ct value } \\
\hline & & & & $\lg M$ & $\operatorname{IgG}$ & & & \\
\hline \multicolumn{9}{|c|}{ Imported = primary case } \\
\hline 0 & Confirmed & 4 July 2015 & 3 & ND & ND & Pos & DENV-1 & 24,09 \\
\hline \multicolumn{9}{|c|}{ Authochtonous case } \\
\hline $1^{\mathrm{a}}$ & Confirmed & 8 Aug 2015 & 6 & Pos & $\mathrm{Neg}$ & Pos & DENV-1 & 24,09 \\
\hline $2^{\mathrm{a}}$ & Confirmed & 8 Aug 2015 & 6 & Pos & Neg & Pos & DENV-1 & 33,47 \\
\hline 3 & Confirmed & 13 Aug 2015 & 3 & ND & ND & Pos & DENV-1 & 20,77 \\
\hline 4 & Confirmed & 18 Aug 2015 & 6 & Pos & Pos & Pos & DENV-1 & 36,39 \\
\hline 5 & Confirmed $^{\mathrm{b}}$ & 8 Aug 2015 & 9 & Pos & Neg & ND & ND & ND \\
\hline 6 & Probable & 12 Aug 2015 & ND & ND & ND & ND & ND & ND \\
\hline 7 & Confirmed & 11 Sep 2015 & 1 & ND & ND & Pos & DENV-1 & 15,52 \\
\hline
\end{tabular}

Ct: cycle threshold; DENV: dengue virus; ND: Not done; Neg: negative; Pos: positive; RT: reverse-transcriptase.

andex case.

${ }^{b}$ Increase of IgM and occurrence of IgG on a second sample performed 15 days after the first sample (antibodies seroconversion).

In total, seven autochthonous dengue cases where identified, six of whom were confirmed while one was probable (Table 1). Fever started from 8 August to 18 August for six cases, including the probable case, and on 11 September for one of the confirmed cases (Figure 1). All cases lived within a $300 \mathrm{~m}$ radius of the residence of the two index cases (Figure 2). The DENV-1 strain was identified for all five cases confirmed by real-time RT-PCR. The sex ratio was $1: 1$, the average age was 38 years old (mean: 38.6 years; range: $16-65$ ). Clinical signs observed were a fever higher than $38.5^{\circ} \mathrm{C}$ $(8 / 8)$, headache $(8 / 8)$, rash $(5 / 8)$, retro-orbital pain (4/8), myalgia (4/8) and digestive disorders (5/8).

\section{Entomological investigation and vector control measures}

It is believed that the area where the cases were living has been colonised by Ae. albopictus since 2011, as it is located close to the places where Ae. albopictus populations were first detected in the city of Nîmes in that same year. The area, composed of small- and mediumsized houses with often interconnected gardens, and harboring many small breeding sites and rainwater collectors, is highly suited to the Ae. albopictus.

After interviewing cases on their movements during the viraemic phase, investigations were undertaken in 23 different sites in seven towns. The presence of vectors (larvae and/or imagos) was detected in 19 of these sites including the outbreak area.

Between 18 August and 12 October 2015, six mosquito control operations (spraying) were performed in the outbreak area (Figure 2). The first operation was performed in a $150 \mathrm{~m}$ radius around the residence of the two index cases. The spraying area was gradually expanded as new cases emerged. Sprayed surface areas ranged from 6.5 ha for the first operation, up to 52 ha for the final sixth operation. The first and second operations included houses of four cases. The other four operations included residences of all identified cases. In all cases except one, clinical signs occurred before or on the same day as the first vector control operations. For that one case clinical symptoms appeared after the third operation (Figure 1).

Investigations in other locations led to 18 mosquito control operations with chemical spraying. The average treated surface for each location was 5.7 ha.

During the door-to-door entomological investigation performed on 20 August, 91 houses were visited and 186 houses were not (151 absences and 35 refusals). A high abundance of $A$ e. albopictus at adult and larval stages was noted. The house index was $42 \%(38 / 91)$, and $20 \%(18 / 91)$ of houses were positive for imagos i.e. presence of at least one adult. The first survey to estimate the prevalence of dengue among mosquitoes lasted 24 hours and took place on 27 August, the day before the second control operation. The second survey lasted from 7 to 11 September, two days before and two days after the third control operation. We trapped 81 and 1,012 (219 males and 793 females) Ae. albopictus, respectively, in the two surveys. The presence of DENV was not detected in any of the 71 analysed pools of Ae. albopictus.

\section{Discussion}

Between 8 August and 11 September 2015, seven autochthonous cases of dengue were identified in the outskirts of Nîmes, a city of ca 150,000 inhabitants [11]. The outbreak, occurred within a $300 \mathrm{~m}$ radius around 
the residence of an imported case, and the virus probably circulated for 3 months.

To date, this has been the largest dengue outbreak reported in mainland France, where only sporadic cases of autochthonous dengue had been reported previously [5-7]. The imported case who tested positive for DENV in July 2015 had returned from French Polynesia and often spent time in the affected district, especially during the viraemic phase. Identification of autochthonous cases of DENV-1 and the absence of other imported cases in the area are two strong arguments that this patient was indeed the primary case. The outbreak occurred in spite of the fact that the number of imported dengue cases was relatively low in 2015. Indeed, 12 imported dengue cases, with five in the Gard administrative district, were recorded in Languedoc-Roussillon region (which includes Gard) between 1 May and 30 November 2015, compared with 32 in 2013 and 24 in 2014 [12].

The outbreak area is quite a densely populated residential zone ( 55 persons per ha) with ca1,100 persons living in a habitat highly suited to Ae. albopictus [13]. Colonised by the vector for at least four years, vector density in the zone is high [14]. The episode investigated here follows a previous outbreak of chikungunya, which is transmitted by the same vector, in Montpellier city, in the Languedoc-Roussillon region in 2014. This confirms the threat of arboviral diseases transmitted by $A e$. albopictus in the Mediterranean region [15].

Vector control measures (i.e. spraying with deltamethrin) had previously been implemented in the areas which the primary case mentioned he had visited and no local transmission of the virus was subsequently detected. However, forgetting to mention just one place in his initial interview was enough for the occurrence of autochthonous transmission in August 2015. This kind of monitoring failure, which is difficult to prevent and which will most likely happen again, highlights the importance of tracking data of the movements of imported cases. On the other hand, all but one case were infected before vector control measures started. The last case, which occurred after all six vector control operations had been implemented, was located on the margins of the treated area. Additional treatment was consequently implemented and no other case was later identified. Vector control measures were applied over a $150 \mathrm{~m}$ radius around the index cases' residence, in accordance with French national guidelines. However, three autochthonous cases and the imported case were located beyond this perimeter. Further work should focus on evaluating the effectiveness of control treatments, and whether control treatment areas should be widened.

Results for DENV detection in mosquitoes were negative. It must be noted, however, that most mosquitotrapping interventions were carried out after the first three mosquito control operations and over the whole investigated area. Recent studies on dengue transmission by Ae. aegypti [16] show a clear correlation between spatial proximity to dengue cases and infected mosquitoes. Therefore, all trapping interventions which aim to screen viruses in vectors should be focused on the immediate vicinity of cases and be implemented as precociously as possible. Considering an average life expectancy of 30 days for female $A e$. albopictus, the 69 day-period between onset of symptoms in the primary case and the last autochthonous case suggests that several generations of mosquitoes were infected $[17,18]$. Furthermore, the absence of notification of autochthonous cases during the month following the onset of symptoms in the primary case could be explained by the occurrence of inapparent illness (ca $75 \%$ of cases in endemic territories) which may play an important role in the transmission chain $[19,20]$. In addition, we cannot exclude the possibility that symptomatic or pauci-symptomatic infections were not detected by the surveillance system. Serological investigation by public health services might lead to greater understanding and documentation of the dynamics of dengue transmission in Mediterranean urban contexts.

\section{Conclusion}

The epidemiology of arboviral diseases depends on multiple factors including environmental, behavioural and individual risk factors, as well as the effectiveness of vector control measures. Since its implementation in 2006, the French national preparedness and response plan to prevent and control local transmission of chikungunya and dengue has led to the detection and containment of several episodes of local transmission of dengue and chikungunya in the country. In the context of the continuing expansion of $A e$. albopictus throughout parts of Europe, autochthonous cases of dengue are detected every year since 2013 with a larger outbreak in 2015 in France and an outbreak of chikungunya occurred in France in 2014 [15]. At a time when Zika virus is spreading in several countries in Central and South America, all highlight the growing risk of arboviral diseases transmitted by Aedes mosquitoes where this vector is established. New guidelines to prevent the spread of arboviral diseases in Europe should be developed and regularly assessed and adjusted to this evolving context. Health authorities need to continue and reinforce provision of information to the general population and travellers and to raise their awareness for the transmission and prevention of arboviral diseases in regions where the vector is established.

\section{Acknowledgements}

The biomedical laboratories Cerba and Biomnis; The laboratory of virology of Nîmes University Hospital; The private laboratories and the general practitioners of the Gard district; P Berthommé, MB Moyano, E Dussere-Berard, O Puech, ARS, France and M Mas, SCHS, France and L Nouguier, Yuste, $\mathrm{P}$ Tourrier, S Estaran, M Micheli, EID Méditerranée, France for contributing to the door-to-door survey; $E$ Le Monnier, M Duhayon, EID Méditerranée, France for contributing to mosquito trapping; L Nouguier, J Yuste, S Larrouy, 
R Lafleur-Ruas, EID Méditerranée, France for contributing to mosquito control operations; I Redini, ARS, France; $\mathrm{H} \mathrm{De}$ Valk, InVS, France

\section{Conflict of interest}

None declared

\section{Authors' contributions}

Contribution to the epidemiological investigations: Tiphanie Succo, Harold Noël, Franck Golliot, Farhad Entezam, Cyril Rousseau, Marie-Claire Paty, Olivier Catelinois, Amandine Cochet

Interviews of the patients: Tiphanie Succo, Farhad Entezam

Implementation of the control measures: Farhad Entezam, Isabelle Esteve-Moussion, Béatrice Broche

Coordination of the control measures: Béatrice Broche, Farhad Entezam

Entomological investigations and coordination of vector control treatment: Jean-Baptiste Ferré, Didier Caire

Laboratory investigations: Isabelle Leparc-Goffart, Marianne Maquart

Coordination of the epidemiological investigations: Tiphanie Succo, Franck Golliot, Cyril Rousseau Harold Noël, MarieClaire Paty

Supervisor of the investigations: Franck Golliot, Cyril Rousseau

Drafted the manuscript: Tiphanie Succo, Cyril Rousseau, Marie-Claire Paty

Contribution to the writing of the paper: Frédéric Jourdain, Christophe Paupy, Jean-Baptiste Ferré, David Roiz, Amandine Cochet, Olivier Catelinois

\section{References}

1. Gubler DJ. Dengue, Urbanization and Globalization: The Unholy Trinity of the 21(st) Century.Trop Med Health. 2011;39(4Suppl):3-11.DOI: 10.2149/tmh.2011-S05 PMID: 22500131

2. Schaffner F, Mathis A. Dengue and dengue vectors in the WHO European region: past, present, and scenarios for the future. Lancet Infect Dis. 2014;14(12):1271-80.DOI: 10.1016/S14733099(14)70834-5 PMID: 25172160

3. Wilder-Smith A, Quam M, Sessions O, Rocklov J, LiuHelmersson J, Franco L, et al. The 2012 dengue outbreak in Madeira: exploring the origins. Euro Surveill. 2014;19(8):20718.DOI: 10.2807/1560-7917.ES2014.19.8.20718 PMID: 24602277

4. Medlock JM, Hansford KM, Schaffner F, Versteirt V, Hendrickx $\mathrm{G}$, Zeller $\mathrm{H}$, et al. A review of the invasive mosquitoes in Europe: ecology, public health risks, and control options. Vector Borne Zoonotic Dis. 2012;12(6):435-47.DOI: 10.1089/ vbz.2011.0814 PMID: 22448724

5. La Ruche G, Souarès Y, Armengaud A, Peloux-Petiot F, Delaunay $P$, Desprès $P$, et al. First two autochthonous dengue virus infections in metropolitan France, September 2010. Euro Surveill. 2010;15(39):19676.PMID: 20929659

6. Marchand E, Prat C, Jeannin C, Lafont E, Bergmann T, Flusin O, et al. Autochthonous case of dengue in France, October 2013. Euro Surveill. 2013;18(50):20661.DOI: 10.2807/1560-7917. ES2013.18.50.20661 PMID: 24342514

7. Giron S, Rizzi J, Leparc-Goffart I, Septfons A, Tine R, Cadiou B, et al. New occurrence of autochthonous cases of dengue fever in Southeast France, August-September 2014. Bull Epidemiol Hebd (Paris). 2015; (13-14):217-23.
8. Gjenero-Margan I, Aleraj B, Krajcar D, Lesnikar V, Klobučar A, Pem-Novosel I, et al. Autochthonous dengue fever in Croatia, August-September 2010. Euro Surveill. 2011;16(9):19805.PMID: 21392489

9. Ministère des affaires sociales, de la santé et des droits des femmes. [Ministry of Social Affairs, health and women's rights.]. Instruction N. ${ }^{\circ}$ DGS/RI1/2015/125 du 16 avril 2015 mettant à jour le guide relative aux modalités de mise en œuvre du plan anti-dissémination du chikungunya et de la dengue en métropole. [Instruction N ${ }^{\circ}$ DGS / RI1 / 2015/125 of 16 April 2015 updating the guide on the implementation modalities of the national preparedness and response plan to prevent and control local transmission of chikungunya and dengue.] Paris: Ministère des affaires sociales, de la santé et des droits des femmes; 2015.

10. Service MW. Mosquito ecology: field sampling methods. 2nd ed. London: Chapman et Hall;1993.

11. Institut national de la statistique et des études économiques (Insee). [National Institute of Statistics and Economic Studies (Insee)]. Populations légales du département du Gard, ses arrondissements, ses cantons et ses communes. [Official population of the Gard district, its boroughs, cantons and communes]. Institut nationale de la statistique et des études économiques. Paris: Insee; 2015 (cited 22 Oct 2015). Available from: http://www.insee.fr/fr/ppp/bases-dedonnees/recensement/populations-legales/departement. asp?dep=30\&annee $=2012$

12. Santé publique France. Chikungunya et dengue - Données de la surveillance renforcée en France métropolitaine. [Chikungunya and dengue - enhancing human surveillance in France]. Updated 5 May 2015, cited 24 May 2015. SaintMaurice: Santé publique France. Available from: http://www. invs.sante.fr/Dossiers-thematiques/Maladies-infectieuses/ Maladies-a-transmission-vectorielle/Chikungunya/ Donnees-epidemiologiques.

13. Jourdain F, Roiz D, Perrin Y, Grucker K, Simard F, Paupy C. [Entomological factors of arboviruses emergences]. Transfus Clin Biol. 2015;22(3):101-6.DOI: 10.1016/j.tracli.2015.06.001 PMID: 26141429

14. Le Préfet du Gard. [Prefecture of the Gard district]. Arrêté préfectoral n²011279-002 du 6 octobre 2011 relatif aux modalities de mise en oeuvre du plan anti-dissémination du chikungunya et de la dengue dans le département du Gard. [Prefectural order No. 2011279-002 of 6 October 2011 on the Modalities of the national preparedness and response plan to prevent and control local transmission of chikungunya and dengue]. 6 Oct 2011. Available from: http://www.gard.gouv. fr/content/download/2416/17437/file/RAA\%202011-10-B\%20 publi\%C3\%A9\%2ole\%206\%200CTOBRE\%20\%202011.pdf

15. Delisle E, Rousseau C, Broche B, Leparc-Goffart I, L'Ambert G, Cochet $A$, et al. Chikungunya outbreak in Montpellier, France, September to October 2014. Euro Surveill. 2015;20(17):21108. DOI: 10.2807/1560-7917.ES2015.20.17.21108 PMID: 25955774

16. Thomas SJ, Aldstadt J, Jarman RG, Buddhari D, Yoon IK, Richardson $\mathrm{JH}$, et al. Improving dengue virus capture rates in humans and vectors in Kamphaeng Phet Province, Thailand, using an enhanced spatiotemporal surveillance strategy. Am J Trop Med Hyg. 2015;93(1):24-32.DOI: 10.4269/ajtmh.14-0242 PMID: 25986580

17. Chan M, Johansson MA. The incubation periods of Dengue viruses.PLoS One. 2012;7(11):e50972.DOI: 10.1371/journal. pone.0050972 PMID: 23226436

18. Delatte H, Gimonneau G, Triboire A, Fontenille D. Influence of temperature on immature development, survival, longevity, fecundity, and gonotrophic cycles of Aedes albopictus, vector of chikungunya and dengue in the Indian Ocean.J Med Entomol. 2009;46(1):33-41.DOI: 10.1603/033.046.0105 PMID: 19198515

19. Bhatt S, Gething PW, Brady OJ, Messina JP, Farlow AW, Moyes $\mathrm{CL}$, et al. The global distribution and burden of dengue. Nature. 2013;496(7446):504-7.DOI: 10.1038/nature12060 PMID: 23563266

20. Duong V, Lambrechts L, Paul R.E, Ly S, Srey Lay R, Long K.C, et al. Asymptomatic humans transmit dengue virus to mosquitoes. Proc Natl Acad Sci U S A. 2015;112(47):14688-93.

\section{License and copyright}

This is an open-access article distributed under the terms of the Creative Commons Attribution (CC BY 4.0) Licence. You may share and adapt the material, but must give appropriate credit to the source, provide a link to the licence, and indicate if changes were made.

This article is copyright of the authors, 2016. 